\title{
SOGLASNIKI STANDARDNE KITAJŠČINE V OKVIRU SLOVENSKEGA GLASOVNEGA SISTEMA*
}

\author{
Mateja PETROVČı̌ \\ Univerza v Ljubljani, Slovenija \\ mateja.petrovcic@ff.uni-lj.si
}

\begin{abstract}
This paper discusses the pronunciation of consonants of Standard Chinese from the perspective of native speakers of Slovenian. Slovenian distinguishes 21 consonants, whereas Chinese distinguishes 22 . Since there are differences in the phonetic features of the two languages in question, this paper examines the strategies of how to map Chinese phonemes to Slovenian sounds. In this process, the principle of rationality plays an important role to avoid unnecessary complications. To achieve this goal, we first outline the categories of Slovenian and Chinese consonants, compare them using the International phonetic alphabet, and propose equivalents for the Slovenian reader. Guidelines for the suggested pronunciation are finally summarized in a short passage.
\end{abstract}

Keywords: Chinese; Hanyu pinyin; consonants; Slovenian; sound system

\section{Povzetek}

Članek obravnava soglasnike standardne kitajščine z vidika govorca slovenskega jezika. Slovenščina ima 21 pomensko razločevalnih soglasnikov, kitajščina enega več. Ker se fonetične značilnosti soglasnikov med jezikoma razlikujejo, prispevek prouči možnosti, kako s slovenskimi glasovi predstaviti kitajske foneme, pri čemer upoštevamo tudi načelo gospodarnosti. $V$ ta namen najprej podamo oris slovenskih in kitajskih soglasnikov, jih primerjamo s pomočjo mednarodne fonetične abecede, predlagamo ustreznice in predlagane rešitve strnemo $v$ krajše navodilo, kako naj slovenski bralec izgovarja kitajske soglasnike.

Ključne besede: kitajščina; pinjin; soglasniki; slovenščina; glasovni sistem

\footnotetext{
* Za strokovni pregled prispevka, korekture in konstruktivne pripombe se zahvaljujem Marti Kocjan Barle, članici Ožjega sestava Pravopisne komisije pri SAZU in ZRC SAZU.
}

Acta Linguistica Asiatica, 9(2), 2019. 


\section{Uvod}

Glasovni sistemi različnih jezikov se med seboj razlikujejo, pri čemer prihaja do razlik med razvrstitvijo in vlogo posameznih prvin glasovnega sistema. $\mathrm{S}$ fonološkega vidika je pomembno, da razumemo, katere foneme imamo na razpolago $v$ določenem jeziku, saj so to najmanjše pomensko razločevalne enote. Zavedati se moramo, da že znotraj istega jezika prihaja do odstopanj med izgovarjavo in zapisom besed. Množice fonemov ne moremo enostavno preslikati v množico grafemov. Pri nekaterih jezikih je odstopanj med izgovarjavo in zapisom besed več, pri drugih manj. Zanima nas, kaj se dogaja pri vstopanju kitajskih besed $v$ slovenski jezik.

Ko besede iz tujega jezika vstopajo v slovenski jezik, jih pogosto najprej zasledimo v pisni obliki. Grafeme interpretiramo v okviru slovenskih glasov, pri čemer upoštevamo nezavedne glasovne procese svojega jezika. Za lažje razumevanje navedimo primer iz angleščine. Če nismo posebej šolani v izgovarjavi angleškega jezika, bomo v angleškoslovenskem slovarju sicer izvedeli, da besedo 'pick' preberemo kot [pIk] in 'pig' kot [pIg], vendar bomo obe besedi samodejno izgovorili kot [pik], saj v slovenščini velja, da črko ' $\mathrm{g}$ ' v izglasju izgovarjamo kot glas [k] (Slovenski pravopis, 2001, § 1069). Enako velja za vse črke za zveneče nezvočnike - izgovarjamo jih nezveneče.

To ne pomeni, da na koncu besede nismo zmožni izgovoriti zvenečega nezvočnika in ustrezno ločiti [pIg] od [pIk], temveč da moramo biti pri učenju angleščine pozorni na to razliko. Gotovo bi tudi znali ustrezno ponoviti izvorno izgovarjavo avtomobilskih znamk 'Peugeot' [pø:'zo] ali 'Renault' [вәno], vendar dobita ti besedi $v$ okviru slovenskih glasov podobo [pežó] in [renó] (gl. FRAN). Na primeru teh dveh besed vidimo, da zaokroženih glasov ne izgovarjamo zaokroženo, francoski grlni / $r$ / pa zamenjamo s slovenskim jezičnikom /r/. Podobno mehkega hrvaškega ali srbskega fonema /ć/ ne izgovarjamo mehko, temveč enako kot fonem /č/ (npr. Andrić [andrič] in Poreč [poreč]). Med značilnosti slovenščine sodi tudi zakonitost, da pred samoglasniki na začetku besede ne izgovarjamo dvoustničnega un, temveč zobnoustnični [v]. Tako angleškega Walden ne preberemo kot ['wว:Idən], temveč kot [vóldən]. ${ }^{1}$

Razumljivo je, da $v$ okviru slovenščine tuje glasove zamenjujemo $z$ najbližjimi slovenskimi knjižnimi glasovi, pri čemer opuščamo vse vrste modifikacij, na primer pri mehčanih in mehkih soglasnikih, posebne vrste zapornikov in podobno (prim. Slovenski pravopis, Pravila, § 222).

Cilj tega prispevka je torej najti slovenske ustreznice za izgovarjavo grafemov za kitajske soglasnike, na katere naletimo $v$ sistemu Hanyu pinyin ali poslovenjeno pinjin. Izraz 'pinjin' je občno ime za točno ta sistem, ki ga je Mednarodna organizacija za standardizacijo sprejela leta 1982, Združeni narodi pa leta 1986. Poleg sistema Hanyu

\footnotetext{
${ }^{1}$ Za ostale podrobnosti o fonemu /v/ gl. § 640-645.
} 
pinyin namreč obstaja tudi Tongyong pinyin, ki se od prvega razlikuje $v$ določenih podrobnostih.

Pri iskanju izgovornih rešitev za kitajske knjižne glasove se skušamo v slovenščini čim bolj približati izvirnemu izgovoru, pri čemer imamo pri presoji v mislih predvsem fonološki vidik. Najpomembneje je, da ohranimo pomensko razločevalne enote. Kjer bi stremenje k preveč dosledni glasovni podobi vodilo do komplikacij, se odločimo za enostavnejše rešitve, saj že $v$ izhodišču vemo, da povsem identične glasovne podobe zaradi omejitev slovenskega glasovnega sistema ne bomo mogli doseči (gl. Slika 1). Slovenski govorec bo torej kitajske zloge v okviru slovenščine izgovarjal po slovensko, med komuniciranjem v kitajščini pa po kitajsko.

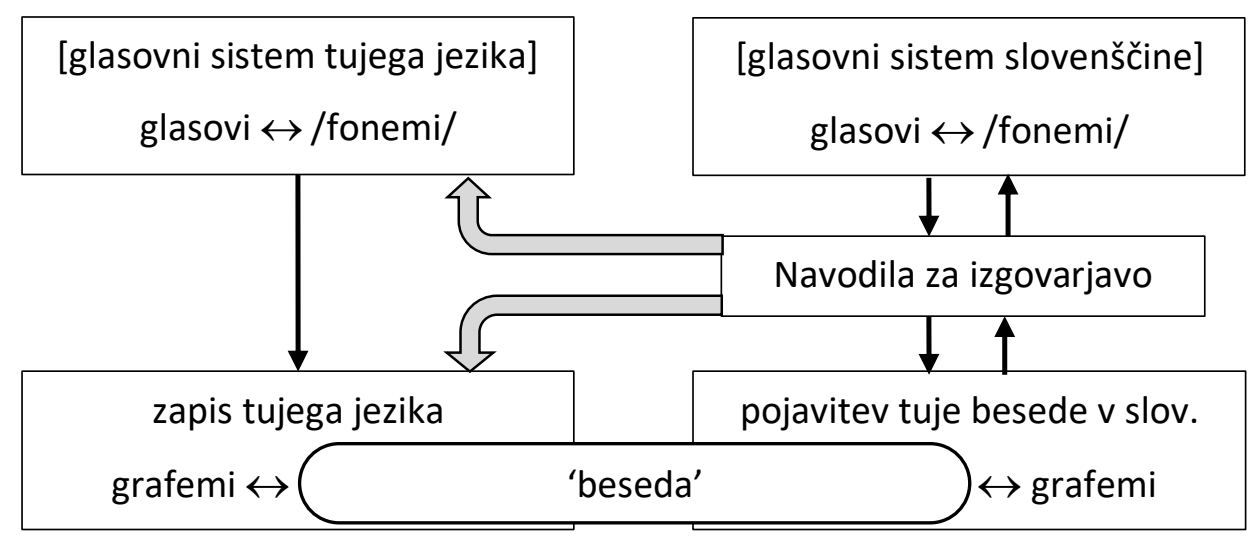

Slika 1: Konceptualni prikaz iskanja rešitev kitajsko-slovenskih ustreznic

Poznavanje glasovnega ustroja materinega jezika nam tudi pomaga razumeti in predvideti, kje bodo pri učenju tujega jezika nastopile težave, saj se moramo v tem procesu spoznati z glasovi in značilnostmi ciljnega jezika, ki se fonetično in fonološko razlikujejo od materinščine. $S$ tega vidika imajo govorci različnih jezikov različne težave pri usvajanju glasovne podobe kitajščine. Poleg aspiracije (pridihnjenosti) imajo govorci angleščine na primer težave z zlitniki (Defense Language Institute, 1974; Comparison of English and Mandarin (Segmentals), 2019), nam povzročajo težave retrofleksni in nebni glasovi, govorcem češčine pa poleg tega še mehkonebni nesičnik pripornik (Švarný \& Uher, 2001; Uher, Jin, \& Slaměníková, 2016). Govorci jezikov, ki ne dopuščajo soglasnikov v izglasju, na primer Telugu (Sailaja, 1999), imajo težave z nosnikoma [n] in

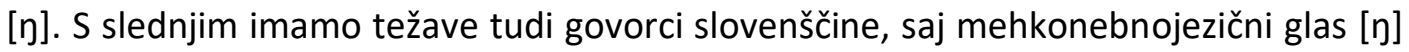
izgovarjamo le na stičišču glasov [n] in [k/g/h] (Anka, Angela, Anhovo), ne pa tudi v izglasju. 


\section{Primerjava soglasnikov $v$ knjižni slovenščini in standardni kitajščini}

\subsection{Oris soglasnikov v slovenščini}

Slovenski knjižni jezik ima 29 pomensko razločevalnih glasovnih enot (fonemov), od tega 8 samoglasnikov in 21 soglasnikov. Nam dobro poznana delitev soglasnikov je:

- zvočniki $(/ \mathrm{m} /, / \mathrm{n} /, / \mathrm{r} /, / \mathrm{l} /, / \mathrm{v} /, / \mathrm{j} /)$

- nezvočniki

$$
\begin{aligned}
& \text { - zveneči }(/ \mathrm{b} /, / \mathrm{d} /, / \mathrm{g} /, / \mathrm{z} /, / z ̌ /, / d z ̌ /) \\
& \text { - nezveneči }(/ \mathrm{p} /, / \mathrm{t} /, / \mathrm{k} /, / \mathrm{s} /, / \mathrm{s} /, / \mathrm{c} /, / \mathrm{c} /, / \mathrm{f} /, / \mathrm{h} /)^{2}
\end{aligned}
$$

Razmerja med glasovi in črkami so natančneje prikazana v $\S 1070$, razmerja med črkami in glasovi pa $v \S 1069$. Zaradi razprave, ki sledi na naslednjih straneh, še enkrat poudarimo, da se glas, fonem in grafem ne prekrivajo $v$ celoti. Izpostavimo nekaj zgledov iz § 1070:

Glas [g] zapisujemo s črko:

- ' $g$ ' (glagol, Bogdan, rog doni) in

- ' $k$ ' pred zvenečim nezvočnikom (kdaj, k domu, vsak dan).

Glas [k] zapisujemo s črko:

- ' $k$ ' (krik, kura, pakt) in

- ' $g$ ' pred nezvenečim nezvočnikom (bogca), $v$ izglasju besede pred premorom (rog), pa tudi pred samoglasnikom ali zvočnikom naslednje besede (rog odmeva, rog joče)

Torej črka ' $\mathrm{g}$ ' zapisuje:

- glas [g] (glagol, Bogdan, rog doni) in

- glas [k] pred nezvenečim nezvočnikom (bogca, rog poje), v izglasju besede pred premorom (rog), pa tudi pred samoglasnikom ali zvočnikom naslednje besede (rog odmeva, rog joče)

Sorodno temu črka ' $k$ ' zapisuje:

- glas [k] (krik, kura, pakt, k tebi, pek odhaja, prek jezera) in

- glas [g] pred zvenečim nezvočnikom (kdaj, k bratu, vsak dan).

Glas [dž], sicer vizualno dve enoti, zapisujemo:

- s črkama 'dž' (džungla),

- s črko 'č' pred zvenečim nezvočnikom (odločba, proč daj) in

- s črko ' $c$ ' pred zvenečima šumevcema ž in dž (stric Žane, stric Džon).

2 Zvočnike si zapomnimo z izrazom mlinarjev, zveneče nezvočnike z izrazom Božo gode džez, nezveneče nezvočnike pa z izrazom ta suhi škafec pušča. 


\subsection{Oris soglasnikov v kitajščini}

Standardna kitajščina ima 22 soglasnikov, ki so glede na mesto artikulacije razporejeni v naslednje skupine:

- dvoustnični /b/, /p/,/m/

- zobnoustnični /f/3

- jezičnokonični /d/, /t/, /n/, /l/, /z/, /c/,/s/

- retrofleksni /zh/, /ch/, /sh/,/r/

- jezično-ploskovni /j/, /q/, /x/

- mehkonebni /g/, /k/, /h/

- mehkonebni nosnik/h/

Vsi soglasniki razen mehkonebnega nosnika / $\mathrm{y} /$ stojijo na začetku zlogov, nosnik /n/ stoji na začetku ali koncu zloga, mehkonebni nosnik /h/, ki ga zapisujemo s črkama 'ng', pa stoji le na koncu zloga.

Med grafemi pinjina sta še črki w in y, ki služita kot vizualno sredstvo za ohranjanje hiata v zlogih tipa GV (drsnik+samoglasnik) (Golob \& Petrovčič, 2018, str. 74). Laično gledano bi rekli, da sta to soglasnika, vendar je njuna raba precej bolj kompleksna.

\section{Fonetični in fonemski zapisi soglasnikov obeh jezikov}

Po številu soglasnikov sta slovenščina in kitajščina zelo primerljiva jezika. Oba imata 21 soglasnikov, pri čemer se kitajski dvaindvajseti soglasnik - mehkonebni nosnik / $/$ / razlikuje od ostalih $v$ tem, da se pojavi le v izglasju.

Da bi lahko proučili oba glasovna sistema, smo ju morali najprej postaviti na skupni imenovalec, saj je nemogoče primerjati dve tako različni klasifikaciji. Kot orodje za ta korak nam je služila Mednarodna fonetična abeceda (IPA).

Namen ozkega fonetičnega zapisa je zapis glasov do take mere, da ohranimo natančno izgovarjavo. Za to uporabljamo oglate oklepaje. Ozki fonetični zapis je laiku težko berljiv. Za boljšo predstavo, kako so zapisane nianse med glasovi, priporočamo ogled naslednjih strani:

- J. Dowse (2018). IPA Charts with Audio. Dosegljivo na https://jbdowse.com/ipa/

- M. Deroń (2018). IPA 2018 i-charts. Dosegljivo na https://linguistics.ucla.edu/people/keating/IPA/inter chart 2018/IPA 2018.html

\footnotetext{
${ }^{3}$ Bopomofo, tajvanski glasovni zapis kitajščine, je dobil svoje ime po prvih štirih elementih tega sistema.
} 
Široki fonetični zapis zajame zgolj najbolj očitne elemente fonetičnega zapisa in prehaja $v$ fonemski zapis. Za fonemski zapis običajno uporabljamo poševnice, pri tem pa sledimo načelu, kako so določeni glasovi v danem jeziku kategorizirani. Meja med fonetičnim in fonemskim zapisom ni vedno jasna in je stvar dogovora. Poglejmo si zapise angleške besede 'red' (rdeč) in kitajske besede 'gua' (buča):

1. podrobni fonetični zapis: $\left[\underline{d}^{\mathrm{w}} \varepsilon \mathrm{d}\right]^{4} \ldots\left[\mathrm{k}^{\mathrm{w}} \mathrm{aa}\right]$

2. osnovni fonetični zapis: $\left[\Lambda^{w} \varepsilon d\right] \ldots\left[k^{w} a\right]$

3. fonetično-fonemski zapis: [^عd] ... [kwa]

4. fonemski zapis: $/ \mathrm{red} /{ }^{5} \ldots / \mathrm{gua} /{ }^{6}$

Na tem mestu si oglejmo primerjavo slovenskih in kitajskih soglasnikov po tretji različici zapisa (Tabela 1 - zaradi boljšega pregleda se celotna tabela nahaja na naslednji strani).

Iz distribucije glasov opazimo, da fonetične razlike med jezikoma niso tako velike. Nosniki, nesični priporniki in stranski drsniki se popolnoma ujemajo. Pri slovenskih zapornikih in sičnikih zlitnikih je pomensko razločevalne narave zvenečnost, pri kitajskih pa aspiracija. Tudi distibucija sičnikov pripornikov je primerljiva s sičniki zlitniki, čeprav obstajajo navidezno večja odstopanja.

Do največjih razhajanj prihaja pri opisu glasu, ki ga v pinjinu zapisujemo s črko ' $r$ '. Li in Thompson (1981, str. 5) navajata, da je to "zveneči retrofleks [ $\lrcorner]$ ", pri čemer je najbrž mišljen zapis $[\lambda]$ in ne $[\Lambda]$, ki se uporablja za zveneči zobnodlesnični drsnik. Duanmu (2007, str. 24) meni, da gre za retrofleksni sičnik pripornik [z], obenem pa navaja, da starejše študije ta glas zapisujejo kot [r]. Tudi Huang (2018) uporablja za zapis [z] ali [ı]. Po pregledu strokovne literature smo se odločili za zapis [z], saj se največ študij nagiba $k$ tej rešitvi.

\footnotetext{
4 [ $]$ ] označuje alveolarni aproksimant, podčrtaj prikazuje, da je glas izgovorjen bolj zadaj v ustih kot običajno, ["] pa signalizira labializacijo oz. zaokroženost ustnic.

${ }^{5}$ Vir: lingvo.info

${ }^{6}$ Vir: Duanmu (2007, str. xi)
} 
Tabela 1: Slovenski in kitajski soglasniki ter njihove vrednosti v Mednarodni fonetični abecedi

\begin{tabular}{|c|c|c|c|c|c|c|c|c|c|c|c|c|c|c|}
\hline \multirow{4}{*}{$\begin{array}{l}\text { mesto artik. } \\
\text { način artik. }\end{array}$} & \multicolumn{14}{|c|}{ izdišni soglasniki } \\
\hline & \multicolumn{4}{|c|}{ ustnični } & \multicolumn{4}{|c|}{ koronalni } & \multicolumn{4}{|c|}{ nebni } & \multirow{2}{*}{\multicolumn{2}{|c|}{$\begin{array}{c}\text { grlni } \\
\text { mehko- } \\
\text { nebni }\end{array}$}} \\
\hline & \multicolumn{2}{|c|}{$\begin{array}{c}\text { dvo- } \\
\text { ustnični }\end{array}$} & \multicolumn{2}{|c|}{$\begin{array}{c}\text { zobno- } \\
\text { ustnični }\end{array}$} & \multicolumn{2}{|c|}{ dlesnični } & \multicolumn{2}{|c|}{ zadlesnični } & \multicolumn{2}{|c|}{ retrofleksni } & \multicolumn{2}{|c|}{ nebni } & & \\
\hline & NN & $\mathrm{ZN}$ & NN & $\mathrm{ZN}$ & NN & $\mathrm{ZN}$ & NN & $\mathrm{ZN}$ & NN & $\mathrm{ZN}$ & NN & $\mathrm{ZN}$ & NN & ZN \\
\hline \multirow{2}{*}{ nosnik } & & $\mathrm{m}$ & & & & $\mathrm{n}$ & & & & & & & & $\eta$ \\
\hline & & $\mathrm{m}$ & & & & $\mathrm{n}$ & & & & & & & & $\eta$ \\
\hline \multirow[t]{2}{*}{ zapornik } & $p$ & $\mathrm{~b}$ & & & $\mathrm{t}$ & $\mathrm{d}$ & & & & & & & $\mathrm{k}$ & $g$ \\
\hline & $\begin{array}{l}p \\
p^{h}\end{array}$ & & & & $t^{\mathrm{h}}$ & & & & & & & & $\begin{array}{c}k \\
k^{h}\end{array}$ & \\
\hline \multirow[t]{2}{*}{ sičnik zlitnik } & & & & & ts & $d z$ & $\mathrm{t} \int$ & d3 & & & & & & \\
\hline & & & & & $\begin{array}{l}\text { ts } \\
\text { ts }^{h}\end{array}$ & & & & $\begin{array}{l}\text { ts } \\
\text { tş }\end{array}$ & & $\begin{array}{l}\mathrm{t} 6 \\
\mathrm{t} 6^{\mathrm{h}}\end{array}$ & & & \\
\hline \multirow[t]{2}{*}{ sičnik prip. } & & & & & $\mathrm{s}$ & z & $\int$ & 3 & & $z$ & & & & \\
\hline & & & & & $s$ & & & & & & 6 & & & \\
\hline \multirow[t]{2}{*}{ nesič. prip. } & & & $f$ & & & & & & & & & & $x$ & \\
\hline & & & f & & & & & & & & & & $x$ & \\
\hline \multirow[t]{2}{*}{ drsnik } & & & & u & & & & & & & & j & & \\
\hline & & & & & & $\lambda$ & & & & 1 & & & & \\
\hline enojni vibr. & & & & & & r & & & & & & & & \\
\hline stran. drsnik & & & & & & $\begin{array}{l}1 \\
1\end{array}$ & & & & & & & & \\
\hline
\end{tabular}

\section{Legenda:}

NN: nezveneči nezvočniki; ZN: zveneči nezvočniki zelena polja: slovenski fonemi modra polja: kitajski fonemi brezbarvna polja: relevantne alofonske uresničitve slovenskih fonemov oranžna obroba: sporne vrednosti kitajskih fonemov

Da bi dosegli sistematično pretvorbo med soglasniki, predlagamo naslednje ustreznice, ki so prikazane v Tabeli 2. 
Tabela 2: Povezave med slovenskimi in kitajskimi soglasniki (fonemi)

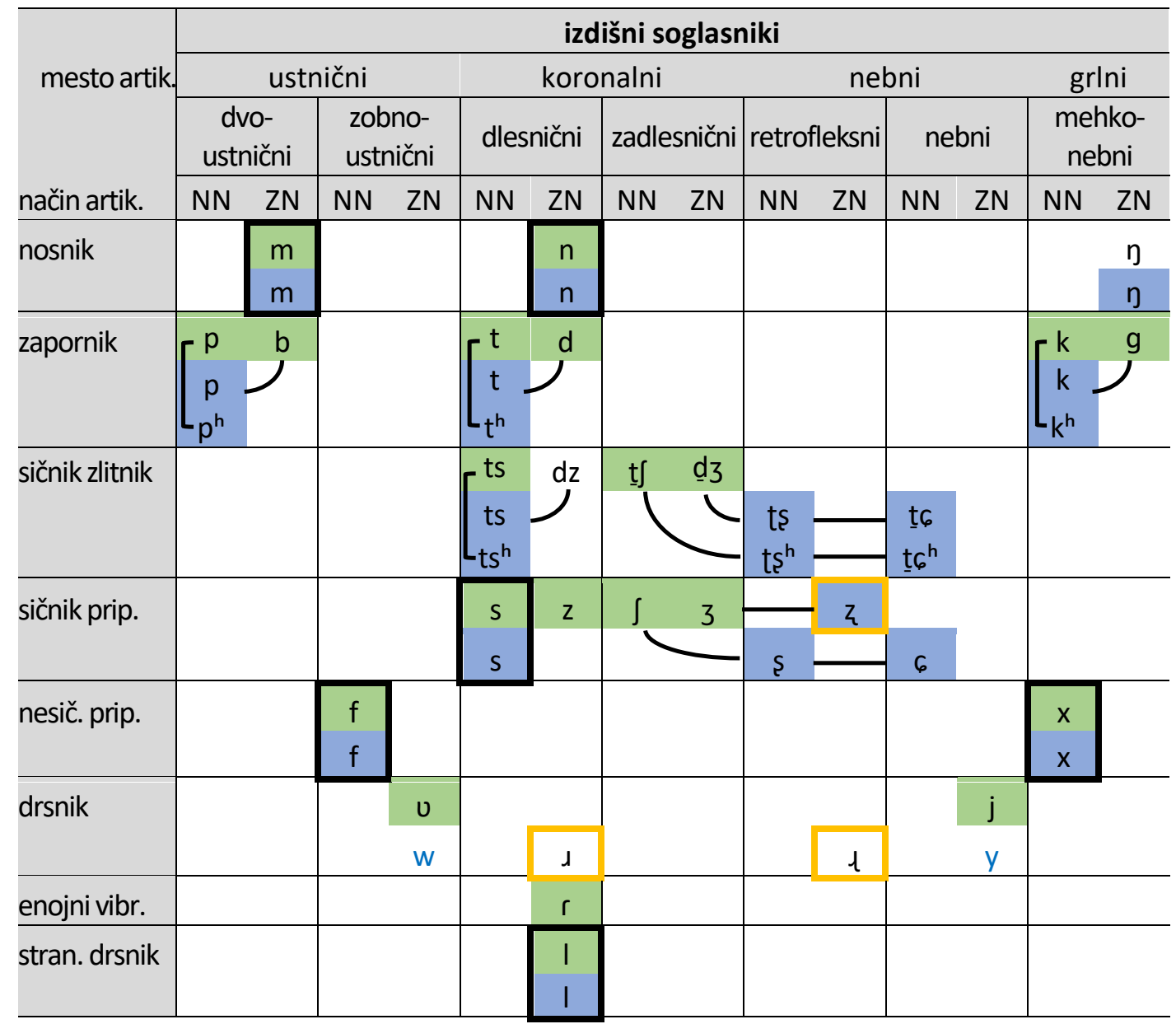

\section{Legenda:}

NN: nezveneči nezvočniki; ZN: zveneči nezvočniki zelena polja: slovenski fonemi modra polja: kitajski fonemi brezbarvna polja: relevantne alofonske uresničitve slovenskih fonemov oranžna obroba: sporne vrednosti kitajskih fonemov

Skoraj vsi soglasniki dobijo svoje enovite ustreznice, izjema so naslednji pari soglasnikov, ki jim pripišemo en sam slovenski soglasnik:

- kitajskima [țc] in [ts] ustreza slovenski [d]3]

- kitajskima [t $\left.\sigma^{\mathrm{h}}\right]$ in [ts $\left.{ }^{\mathrm{h}}\right]$ ustreza slovenski [t $\left.\mathrm{t}\right]$

- kitajskima [6] in [s] ustreza slovenski []]

Za lažjo razumljivost te rešitve poenostavimo fonetično-fonemski zapis v fonemski zapis (Tabela 3). 
Tabela 3: Povezave med slovenskimi in kitajskimi soglasniki (grafemi)

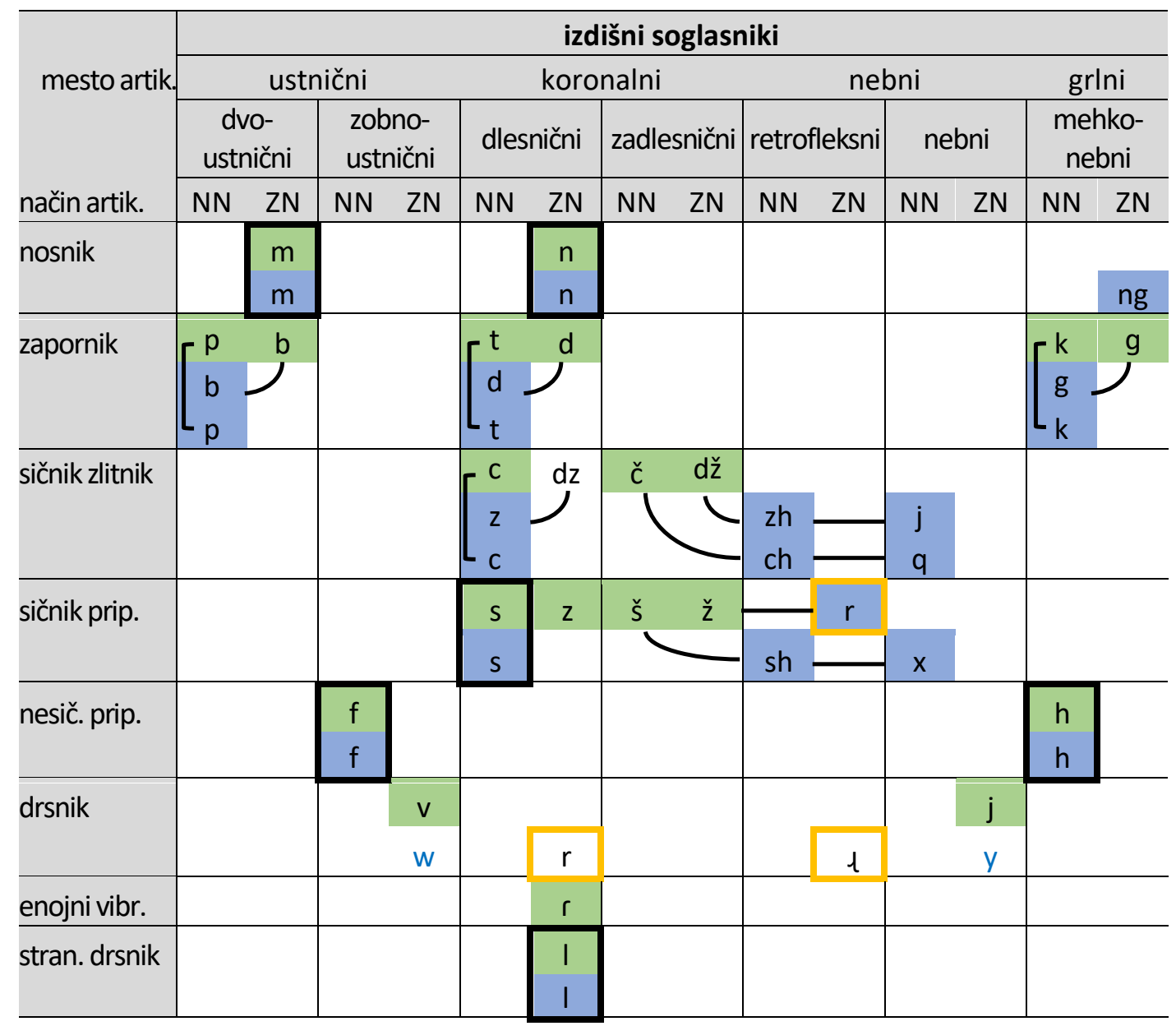

\section{Legenda:}

NN: nezveneči nezvočniki; ZN: zveneči nezvočniki

zelena polja: slovenski fonemi

modra polja: kitajski fonemi

brezbarvna polja: relevantne alofonske uresničitve slovenskih fonemov

oranžna obroba: sporne vrednosti kitajskih fonemov

Do odločitve, da pare $c h-q, s h-x$ in $z h-j$ združimo $v$ isti soglasnik, smo prišli po proučitvi teh glasov $v$ vseh zlogih standardne kitajščine. Analiza je pokazala, da so ti soglasniki $v$ popolni komplementarni distribuciji. Na primer, pred končajem $-a$ lahko stojijo le $z h / c h / s h$, pred končajem -i $a^{7}$ pa samo $j / q / x$. Slovenska izgovarjava [ča] ustreza kitajskemu cha, slovenska izgovarjava [čja] pa kitajskemu qia.

V prid tej rešitvi, ki ne sledi zgolj fonetični podobi jezika, temveč upošteva tudi grafično reprezentacijo, govori tudi minimalno odstopanje med črkami. Nesmislelno bi bilo stremeti $k$ identični glasovni podobi in kitajskemu ' $b$ ' pripisati slovenski ' $p$ ',

\footnotetext{
${ }^{7} \mathrm{~V}$ kitajščini se zapis -ia bere kot drsnik in samoglasnik [ja].
} 
kitajskemu ' $p$ ' pa dodajati črko $h$ za doseganje aspiracije 'ph'. S tem bi se obenem že nekoliko oddaljili od željenega $\left[\mathrm{p}^{\mathrm{h}}\right]$. Če bi že na vsak način želeli dodati informacijo o pridihnjenosti, bi lahlo uporabili sočno prispodobo, ki jo ponuja Golob.

"Da b'te koklja brcnila!« Hvalabogu za zapornike, saj so odlični blažilci stresa, pa tudi izrazne fleksibilnosti jim ne manjka! Moč čustvene napetosti tako lahko izrazimo z bojem med iztiskanjem zraka in tesno zaprtimi ustnicami, za katerimi lahko pritisk naraste tudi do meje, ko obraz pordeči. Takrat nekoliko popustimo togost ustnic, da lahko glasove obogatimo z veliko mero piša (aspiracije) in učinek je zagotovljen: [,phorkha'dhu]].

Na tem mestu omenimo še eno podrobnost glede zapisa v oglatih oklepajih. Čeprav se načeloma med oglate oklepaje piše fonetični in ne fonemski zapis, v slovenski razlagi izgovarjave uporabljamo slednjega, pri čemer upoštevamo tudi zgoraj omenjena razmerja med glasom in črko.

Spomnimo se, da črka 'g' zapisuje glas 'k' pred nezvenečim nezvočnikom. Po tem principu švedsko besedo 'ángstrem' oz. 'ångström' zapišemo [ánkstrem]. Podobno tudi angleško besedo 'Iongplay' zapišemo [lônkplêj].

Pričakovali bi, da bodo v skladu s $§ 1069$ tudi črke 'g' na koncu besede zapisane kot [k], vendar novejše smernice uporabljajo mnogo boljšo rešitev:

benchmarking [bênčmárking-]

bôdibílding in bodybuilding [bôdibílding-]

bowling [bôunling-] (FRAN)

Iz tega zapisa je jasno razvidno, da pri pregibanju ohranjamo [g], obenem pa vemo, da se $v$ imenovalniku zadnji glasovi teh besed preberejo kot [k]. Razumevanje takega zapisa razreši vse dileme, kako zapisovati kitajske zloge, ki se končajo na -ng. Priimek 'Chang' tako zapišemo [čáng-] in ne [čánk]. Razumljivo postane tudi, zakaj ime kitajkega astronoma Wang Chonga zapišemo kot [vánk čúng-] in ne kako drugače.

Poznavanje prilikovanjskih (asimilacijskih) procesov je koristno ne le znotraj lastnega jezika, temveč tudi pri učenju in poučevanju tujih jezikov. Na vsaj srednji zahtevnostni stopnji bi se morali učenci/študenti zavedati, da prihaja $v$ besedah shénme ali guăngbō do sprememb izgovarjave. Za celovitejše razumevanje te tematike bi bilo koristno izdelati primerjalno študijo glasovnih procesov obeh jezikov. 


\section{Zaključek}

Po številu soglasnikov sta slovenščina in kitajščina primerljiva jezika, ki se razlikujeta predvsem po pomensko-razločevalni funkciji zvenečnosti in pridihnjenosti. Predlagane rešitve iz Tabele 3 strnimo v krajše navodilo, primerno za slovenskega bralca, ki skuša prebrati zapis soglasnikov v pinjinu v okviru slovenskih knjižnih glasov.

1. Črke $b, c, d, f, g, h, k, l, m, n, p, s$ in $t$ izgovarjamo tako kot v slovenščini.

2. Razlika med zapisom v pinjinu in izgovorom v slovenščini:

\begin{tabular}{|c|c|}
\hline pinjin & izgovo \\
\hline$r$ & [ž] \\
\hline$c h, q$ & {$[\check{c}]$} \\
\hline$s h, x$ & [š] \\
\hline$z h, j$ & [dž] \\
\hline$z$ & {$[\mathrm{dz}]$} \\
\hline$w$ & {$[\mathrm{v}]$} \\
\hline$y$ & [j] \\
\hline$n g$ & [ng-] \\
\hline
\end{tabular}

Poudariti moramo, da zgolj taka oblika zapisa navodil za izgovarjavo soglasnikov še ni dovolj, saj potrebujemo pregled vseh končajev in njihove kombinacije s soglasniki v vzglasju. Zaradi večplastnosti in obsežnosti problematike ta del raziskave $v$ okviru Pravopisne komisije pri SAZU in ZRC SAZU še ni zaključen.

\section{Sofinanciranje raziskave}

Pričujoči prispevek je sofinancirala Javna agencija za raziskovalno dejavnost Republike Slovenije (ARRS) iz državnega proračuna v okviru raziskovalnega programa št. P6-0243 Azijski jeziki in kulture.

\section{Reference}

Chinese pronunciation wiki (2015-2018). IPA. Dosegljivo na https://resources.allsetlearning.com/chinese/pronunciation/IPA

Comparison of English and Mandarin (Segmentals). (2019). A Corpus-based English Pronunciation Learning Website. The Education University of Hong Kong. Dosegljivo na http://corpus.eduhk.hk/English Pronunciation/?page id=328

Defense Language Institute (1974). A Contrastive Study of English and Mandarin Chinese. Washington, D.C.: ERIC Clearinghouse. 
Deroń, M. (2018). IPA 2018 i-charts. Dosegljivo na

https://linguistics.ucla.edu/people/keating/IPA/inter chart 2018/IPA 2018.html

Dowse, J. (2018). IPA Charts with Audio. Dosegljivo na https://jbdowse.com/ipa/

EasyPronunciation.com (2013-2019). Chinese Pronunciation Tool - Pinyin Translator. Dosegljivo na https://easypronunciation.com/en/chinese-pinyin-phonetic-transcriptionconverter\#phonetic transcription

Golob, N. (neobjavljeno). Glasovna podoba japonskega jezika.

Golob, N., \& Petrovčič, M. (2018). Hokkaido Pumpkins and Huawei Phones: Anti-hiatus Tendencies in Slovene. Acta Linguistica Asiatica, 8(2), 63-82.

https://doi.org/10.4312/ala.8.2.63-82

Huang, K. (2018). Phonological Identity of the Neutral-tone Syllables in Taiwan Mandarin: An Acoustic Study. Acta Linguistica Asiatica, 8(2), 9-50. https://doi.org/10.4312/ala.8.2.9-50

International Phonetic Association, (Ur.) (1999). Handbook of the International Phonetic Association. Cambridge: Cambridge University Press.

Li, C. N., \& Thompson, S. A. (1981). Mandarin Chinese: A functional reference grammar. Berkeley: Univ. of California Press.

Lingvo.info (2019) Fonetika, inventar zvokov. Zvoki, ki jih govorimo. Dosegljivo na http://lingvo.info/sl/babylon/phonetics

Sailaja, P. (1999) Syllable Structure of Telugu. 14th International Congress of Phonetic Sciences (ICPhS-14), 743-746. Dosegljivo na

https://www.internationalphoneticassociation.org/icphsproceedings/ICPhS1999/papers/p14 0743.pdf

Švarný, O., \& Uher, D. (2001). Hovorová čínština: úvod do studia hovorové čínštiny. 2. Olomouc: Univerzita Palackého.

Toporišič, J. (ur.) (2001). Slovenski pravopis. Ljubljana: Slovenska akademija znanosti in umetnosti in Znanstvenoraziskovalni center SAZU, Inštitut za slovenski jezik Frana Ramovša. Dosegljivo na http://bos.zrc-sazu.si/c/sp/sp2001 pravila.pdf

Uher, D., Jin, X., \& Slaměníková, T. (2016). Učebnice čínské konverzace II. Praha: Leda. 